\title{
TINGKAT PENGELOLAAN LIMBAH B3 PADA INDUSTRI PARIWISATA DI KECAMATAN KUTA SELATAN
}

\author{
Ajeng Hayuanandra \\ Program studi Teknik Industri, Fakultas Teknik, Universitas Mahendradatta \\ Jl.Ken Arok No.12, Peguyangan, Denpasar, Bali 80115 \\ Email: Aiyyuanandra@gmail,com
}

\begin{abstract}
Abstrak - Kecamatan Kuta Selatan merupakan sentra pariwisata di Bali ditandai dengan tingginya kepadatan dan perluasan pembangunan terutama industri pariwisata. Kegiatan industri pariwisata khususnya akomodasi wisata di Kecamatan Kuta Selatan pada tahun 2018 adalah sebanyak 329 hotel melati, 33 hotel bintang lima , 12 hotel bintang empat, 12 hotel bintang tiga dan 6 hotel bintang dua serta banyaknya 150 pondok wisata atau villa (BPS,2019). Operasional harian hotel menghasilkan Limbah B3 berupa limbah bekas elektronik seperti lampu LED, sisa pelumas dan bekas wadah bahan bahan. Limbah B3 khususnya bahan elektronik bekas mengandung logam berat seperti merkuri, timbal, lithium dan cadmium. Tujuan dari penelitian ini adalah untuk mengetahui seberapa jauh industri pariwisata di Kuta Selatan, terutama hotel dan pondok wisata telah mengimplmentasikan pengelolaan limbah B3. Pengelolaan limbah B3 terdiri dari perijinan, pewadahan, penyimpanan, pengumpulan dan pengelolaan lanjutan. Perijinan dan penyimpanan sementara adalah langkah pertama pengelolaan limbah B3 yang wajib dilakukan penghasil limbah B3. Berdasarkan hasil penelitian akomodasi wisata dengan jumlah kamar diatas 400 unit semuanya telah memilki ijin tempat penyimpanan sementara limbah B3. Sementara hotel dengan kapasitas kamar 300-400 unit sebanyak $70 \%$ telah memiliki ijin penyimpanan sementara limbah B3. Hotel dengan kapasitas kamar 100-300 unit sebanyak $50 \%$ telah memiliki ijin tempat penyimpanan sementara limbah B3. Sedangkan hotel atau villa dengan unit kamar dibawah 100 hanya $4 \%$ yang sudah memiliki ijin tempat penyimpanan sementara limbah B3.
\end{abstract}

Kata Kunci : Pengelolaan Limbah B3, Akomodasi Wisata, Kecamatan Kuta Selatan

Abstract - Kuta Selatan subdistrict is one of the tourism hotspots in Bali, as shown by the rates of development in the economic sector, especially in the tourism industry. The numbers of accommodations in Kuta Selatan, from 2018 data, are 329 non-star hotel, 33 five star hotels, 12 four star hotels, 12 three star hotels, 12 four star hotels and approximately 150 private villas (BPS,2019). Daily operation of hotels produces hazardous waste such as electronic waste, LED light, oil and chemical containers. Electronic waste is content with heavy metal such as mercury, lead, lithium and cadmium. Hazardous wastes that are released into the environment without any treatment can be harmful for public health. The purpose of this research is to know how far tourism industries, especially hotels and private villas, have implemented the requirements for hazardous waste management. Hazardous waste management consists of permits, container, storage, collection and treatment. Permits and temporary hazardous waste storage are mandatory requirements for hotels to have as a first step of the whole process of hazardous waste management. Based on the data collection from 150 samples, we are shown that $70 \%$ of hotels with a capacity of 300-400 rooms already have hazardous waste temporary storage as well as the permit. With smaller scale hotels, only $50 \%$ already have hazardous waste temporary storage, as well as the permit. In contrast, in small scale accommodation, such as hotels with a capacity under 100 rooms, and private villas, only $4 \%$ have proper hazardous waste temporary storage.

Keywords : Hazardous Waste Management, Tourist Accommodation, Kuta Selatan District 


\section{PENDAHULUAN}

Kecamatan Kuta Selatan merupakan sentra pariwisata di Bali ditandai dengan tingginya kepadatan dan perluasan pembangunan terutama industri pariwisata. Kegiatan industri pariwisata khususnya akomodasi wisata di Kecamatan Kuta Selatan pada tahun 2018 adalah sebanyak 329 hotel melati, 33 hotel bintang lima , 12 hotel bintang empat, 12 hotel bintang tiga dan 6 hotel bintang dua serta banyaknya 150 pondok wisata atau villa (BPS,2019) . Operasional harian hotel menghasilkan Limbah B3 berupa limbah bekas elektronik seperti lampu LED, sisa pelumas dan bekas wadah bahan bahan. Limbah B3 khususnya bahan elektronik bekas mengandung logam berat seperti merkuri, timbal, lithium dan cadmium. Tujuan dari penelitian ini adalah untuk mengetahui seberapa jauh industri pariwisata di Kuta Selatan, terutama hotel dan pondok wisata telah mengimplmentasikan pengelolaan limbah B3. Pengelolaan limbah B3 terdiri dari perijinan, pewadahan, penyimpanan, pengumpulan dan pengelolaan lanjutan. Perijinan dan penyimpanan sementara adalah langkah pertama pengelolaan limbah B3 yang wajib dilakukan penghasil limbah B3.

Pengelolaan limbah B3 telah diatur UndangUndang Republik Indonesia Nomor 32 Tahun 2009 Tentang Perlindungan dan Pengelolaan Lingkungan hidup, menyebutkan bahwa setiap orang yang berada di wilayah Negara Kesatuan Republik Indonesia, menghasilkan, mengangkut, mengedarkan, menyimpan, memanfaatkan, membuang, mengolah, dan/atau menimbun B3 wajib melakukan pengelolaan B3. Akan tetapi karena terbatasnya informasi mengenai pengelolaan limbah B3, masih banyak bentuk pengelolaan limbah B3 yang masih jauh dari standar.

\section{METODE PENELITIAN}

Pelaksanakaan pengumpulan data untuk mengetahui tingkat penanganan limbah B3 di Industri pariwsisata di Kuta Selatan dikhususkan pada akomodasi wisata dikarenakan akomodasi wisata menghasilkan limbah B3 yang paling banyak dibandingkan dengan jenis industry pariwisata lainnya.

\section{- Wawancara/kuisioner}

Wawancara/kuesioner adalah teknik pengumpulan data yang dilakukan dengan cara memberikan seperangkat pertanyaan atau pernyataan kepada orang lain yang dijadikan responden untuk dijawabnya. Instrumen yang digunakan berupa lembar pertanyaan (kuesioner). Data yang hendak diketahui dengan menggunakan metode ini adalah prakiraan jumlah limbah B3 yang dihasilkan, Kualitas limbah B3 dan tata cara penyimpanan

\section{- Survei / Penelitian Lapangan}

Dilakukan untuk memperoleh data primer yang diperlukan dalam analisa,yaitu dokumentasi, jumlah dan lokasi usaha atau kegiatan dan usaha pengelolaan limbah yang telah berjalan dan juga survey dilakukan untuk mengetahui kondisi pembuangan limbah B3. Dalam penelitian ini observasi dilakukan secara non participant, yaitu peneliti tidak ikut secara langsung dalam kegiatan atau proses yang sedang diamati, namun menempatkan diri sebagai pengamat dan mencatat berbagai peristiwa yang dianggap perlu sebagai data pemantauan sumber pencemar. Alat yang digunakan dalam teknik observasi ini antara lain : lembar cek list, buku catatan, kamera photo dan GPS. Sebelum melakukan survei terlebih dahulu telah diperoleh data kegiatan/usaha yang terdapat di tiga kecamatan, kemudian dilakukan verifikasi di lapangan.

\section{HASIL DAN PEMBAHASAN}

\section{Sumber Limbah B3 dari Kegiatan Hotel}

Limbah B3 yang dihasilkan dari kamar dan housekeeping secara umum antara lain ; bekas kemasan produk pembersih kimia, seperti pembersih berbahan ammonia, pembersih saluran, pengkilam furniture, pembesih kaca dan pembersih toilet. Baterai yang hanya dipakai sekali yang biasanya terbuat dari alkali-mangan atau zinc-oxides, yang berada di senter, speaker dan jam dinding.

Baterai yang berada pada kamera, jam dan kalkulatur terbuat dari perak oksida, zinc, lithium alkaline dan merkuri oxide. Baterai yang dapat diisi ulang, terbuat dari nikel cadmium, nikel 
metal hibrida, Lampu TL atau lampu yang menggunakan fluorescent mengandung logam berat yakni merkuri dan tidak dapat dibuang ke landfill. Sisa lukisan dan solvent, yang mengandu ng High Volatile Organic Compound (VOC)

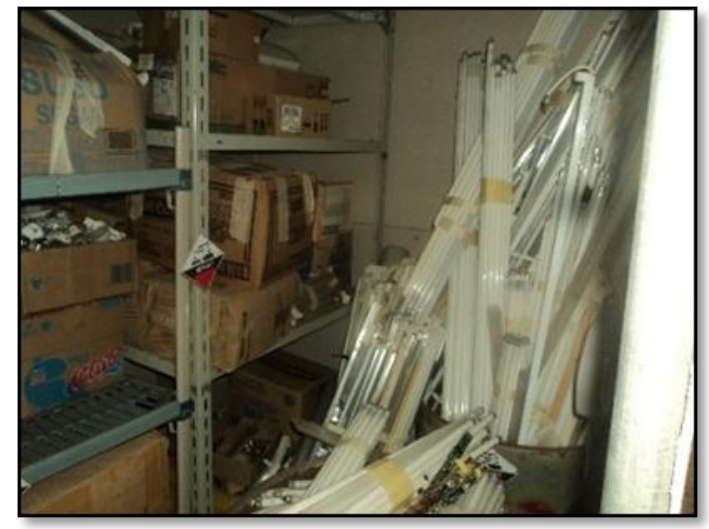

Gambar 1 Sisa Lampu TL yang tidak diwadahi

Sumber Limbah B3 pada hotel yang bersumber dari kantor biasanya dari cartridge printer, $\mathrm{PCB}$ dan barang-barang eletronik rusak lainnya. Limbah yang bersumber dari workshop MEE antara lain pelumas, kain majun, kerosin, aku dan antri-freeze. Limbah dari kegiatan pencucian/laundry antara lain sisa deterjen, bleaching khususnya untuk sprei dan handuk yang berwarnma putih.

Limbah dari fasilitas kolam renang antara lain Bahan-bahan kimia yang biasana digunakan dalam perawatan kolam renang antara lain PAC (Poly Aluminium Chloride) atau tawas, Soda Ash, Trussi (Copper Sulphate) yang berfungsi untuk mencegah pertumbuhan lumut dan chlorine sebagai desinfektan.

\section{Jenis Limbah B3 yang dihasilkan}

bahwa limbah B3 yang paling banyak dihasilkan adalah aki bekas yakni sebesar $34 \%$, Lampu bekas sebesar $22 \%$, Oli bekas sebesar $18 \%$, Baterai sebesar $13 \%$, dan kemasan bekas B3 sebesar $9 \%$ sementara sisanya berupa filter oli, kain majun dan cartridge bekas. Gambaran mengenai prosentasi jenis limbah yang dihasilkan dapat dilihat pada Gambar berikut ini :

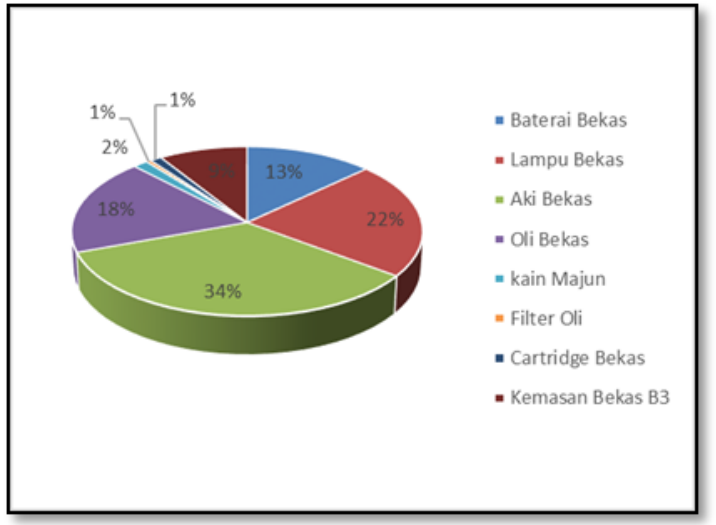

Gambar 2 Prosentase Jenis Limbah yang dihasilkan

3. Hotel yang telah Memiliki ljin Penyimpanan Sementara Limbah B3

Berdasarkan hasil survei yang dilakukan diketahui bahwa rata-rata hotel dengan kategori berbintang telah memiliki fasilitas penyimpanan sementara limbah B3 dan izin limbah B3. Sementara untuk vila atau pondok wisata masih belum memiliki penyimpanan sementara limbah B3 dan tidak melakukan pengelolaan. Hotel dengan kapasitas kamar diatas 400 kamar yang iasanya kategori bintang 4 dan 5 sebanyak 100 $\%$ telah memiliki ijin penyimpanan sementara limbah B3 dan telah memiliki fasilitas penyimpanan sementara. Sedangkan hotel dengan kapasitas kamar sebanyak 300-400 kamar sebanyak $71 \%$ telah memiliki ijin penyimpanan limbah B3. Sedangkan hotel dengan kapasitas 100-300 kamar sebagian yakni $50 \%$ telah memiliki ijin penyimpanan sementara limbah B3 dan sisanya belum memiliki atau sedang dalam proses. Sedangkan villa atau hotel dengan kamar berjumlah diabwah 100 hanya sebagian kecil saja yang telah memiliki penyimpanan limbah B3. Informasi mengenai kegiatan yang telah memiliki penyimpanan limbah B3 diharapkan agar dapat memeberikan gambaran mengenai fokus penanganagn pengelolaan limbah B3 terutama untuk kegiatan dengan skala yang kecil seperti pondok wisata atau hotel dengan jumlah kamar yang sedikit. Gambaran mengenai kondisi penyimpanan limbah B3 dapat dilihat pada diagram balok berikut ini : 


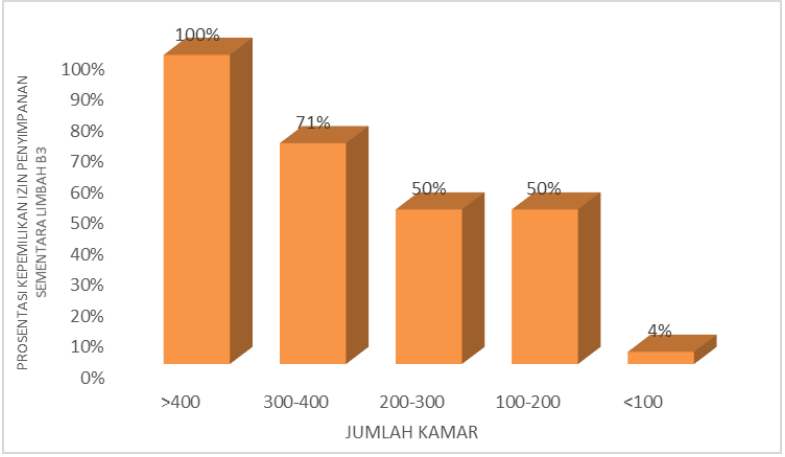

Gambar 3 Tingkat kepemilikan ijin penyimpanan sementara Limbah B3

4. Penyebab hotel belum memiliki ljin penyimpanan B3

Menurut hasil survei menunjukkan bahwa sebesar $70 \%$ dari hotel di Kuta Selatan terutama villa dan hotel berskala kecil hanya menghasilkan sedikit volume limbah B3 dan kurang paham mengenai kewajiban untuk melakukan pengelolaan dengan menyedikan fasilitas penyimpanan sementara. Sedangkan sebanyak $19 \%$ telah memiliki fasilitas penyimpanan sementara namun tidak memiliki ijin penyimpanan sementara dan sisanya masih dalam tahap pengurusan atau sudah memiliki namun kondisi kurang baik. Berikut ini adalah diagram prosentase alasan mengenai kegiatan yang belum memiliki ijin penyimpanan limbah B3.

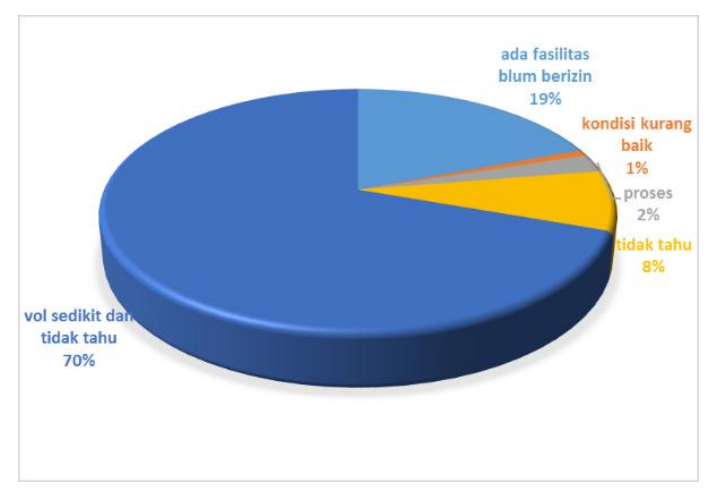

Gambar 4 Penyebab akomodasi belum memiliki ijin penyimpanan

\section{Kondisi Penyimpanan Sementara Limbah B3}

Penyimpanan sementara limbah B3 harus dilakukan jika limbah B3 tersebut belum dapat diolah dengan segera. Kegiatan penyimpanan sementara limbah B3 dimaksudkan untuk mencegah terlepasnya limbah B3 ke lingkungan sehingga potensi bahaya terhadap manusia dan lingkungan dapat dihindarkan. Untuk meningkatkan pengamanannya, maka sebelum dilakukan penyimpanan sementara limbah B3 harus terlebih dahulu dikemas. Mengingat keragaman karakteristik limbah B3, maka dalam pengemasannya perlu pula diatur tata cara yang tepat sehingga limbah dapat disimpan dengan aman.

Penilaian kondisi penyimpanan sementara Limbah B3 dilakukan ke seluruh akomodasi yang dilakukan survei dan mengisi kuesioner.

\subsection{Kondisi Pewadahan}

Kondisi Pengemasan limbah B3 pada penyimpanan sementara Bentuk pengemasan yang baik harus mengikuti persyaratan umum pengemasan dan prinsip pengemasan yakni sebagai berikut : kemasan limbah B3 harus dalam kondisi baik, tidak rusak dan bebas dari karat serta kebocoran.Bentuk, ukuran dan bahan kemasan disesuaikan dengan karakteristik limbah yang akan dikemas dengan mempertimbangkan segi keamanan dan kemudahan penanganannya. Bahan kemasan dapat terbuar dari bahan plastik HDPE,PP,PVX atau bahan logam (teflon, baja karbon). Limbah yang tidak kompatibel atau tidak layak campur tidak boleh disimpan secara bersama-sama dalam satu kemasan. Untuk mencegah terjadinya bahaya selama penyimpanan, maka jumlah pengsisian limbah dalam kemasan harus mempertimbangkan kemungkinan terjadinya pengembangan volume limbah, pembentukan gas atau terjadinya kenaikan tekanan. Jika, kemasan yang berisi limbah sudah dalam kondisi kurang layak (terjadi karat, kebocoran atau kerusakan permanen), maka limbah harus dipindahkan ke dalam kemasan lain yang memenuhi syarat. Kemasan yang berisi limbah harus diberi symbol limbah B3 atau label limbah B3 yang sesuai dan disimpan dengan tata cara dan persyaratan penyimpanan limbah, yang setidaknya terdiri dari nama limbah B3, identitas penghasil limbah B3, tanggal dihasilkannya limbah B3, tanggal pengemasan limbah B3 
Hasil pengisian kuesioner mengenai pengemasan limbah B3 menunjukkan rata-rata kondisi pengemasan cukup baik yakni tidak ada kebocoran. Sementara hanya 49 fasilitas memiliki ukuran kemasan yang sesuai, biasanya disebabkan ukuran lampu TL yang panjang dan tidak ada wadah yang sesuai. Bahan kemasan yang digunakan rata-rata adalah HDPE,PP,PE dan PVC untuk limbah padat dan logam untuk limbah cair. Pelabelan rata-rata juga sudah dilakukan dan penutupan kemasan limbah B3. Namun hanya 36 yang memberikan ruang kosong di dalam kemasan penyimpanan limbah B3.

Tabel 1 Kondisi Pewadahan LB3

\begin{tabular}{|l|c|r|}
\hline \multicolumn{1}{|c|}{ Pengemasan B3 } & $\begin{array}{c}\text { Jumlah } \\
\text { akomodasi }\end{array}$ & $\begin{array}{c}\% \text { dari } \\
\text { total } \\
\text { sampel }\end{array}$ \\
\hline Kondisi Kemasan baik & 57 & $38 \%$ \\
\hline $\begin{array}{l}\text { Ukuran Kemasan } \\
\text { sesuai }\end{array}$ & 46 & $31 \%$ \\
\hline Bahan kemasan sesuai & 49 & $33 \%$ \\
\hline Limbah tidak dicampur & 49 & $33 \%$ \\
\hline Ada Pelabelan & 48 & $32 \%$ \\
\hline Ada Penutup & 46 & $31 \%$ \\
\hline Ada Ruang Kosong & 36 & $24 \%$ \\
\hline
\end{tabular}

\subsection{Bangunan Penyimpanan}

Bangunan penyimpanan kemasan limbah B3 sebaiknya memenuhi persyaratan sebagai berikut ini. Memiliki rancang bangun dan luas ruang penyimpaan yang sesuai dengan jenis,karakteristik dan jumlah limbah B3 yang akan disimpan. Terlindung dari masuknya air hujan, baik secara langsung maupun tidak langsung.Dibuat tanpa plafon dan memiliki sistem ventilasi udata yang memadai untuk mencegah terjadinya akumulasi gas di dalam ruang penyimpanan, serta memasang kasa atau bahan lain untuk mencegah masuknya burung atau binatang kecil lainnya ke dalam ruang penyimpanan.Memiliki sistem penerangan (lampu/cahaya) yang memadai untuk operasional penggudangan atau inspeksi rutin. Jika menggunakan lampu, maka lampu penerangan harus dipasangan minimum $1 \mathrm{~m}$ diatas kemasan dengan sakelar terpasang di sisi luar bangunan.Lantai bangunan penyimpanan harus kedap air, tidak bergelombang, kuat dan tidak retak. Lantai bagian dalam dibuat melandai turun ke arah bak penampungan dengan kemiringan maksimum $1 \%$. Pada bagian luar bangunan, kemiringan lantai diatur sedemikian rupa sehingga air hujan dapat mengalir ke arah yang menjauhi bangunan penyimpanan. $T$ empat penyimpanan yang digunakan untuk menyimpan lebih dari satu jenis limbah B3 dengan karakteristik berbeda, maka ruang penyimpanan harus terdiri atas beberapa bagian penyimpanan, dengan ketentuan bahwa setiap bagian penyimpananhanya diperuntukkan menyimpan satu jenis limbah B3 atau limbah-limbah B3 yang saling cocok. Antara bagian penyimpanan satu dengan lainnya harus dibuat tanggul atau tembok pemisah untuk menghindarkan tercampurnya atau masuknya tumpahan limbahan B3 ke bagian penyimpanan lainnya. Setiap bagian penyimpanan masing-masing harus mempunyai bak penampung tumpahan limbah dengan kapasitas yang memadai. Sistem dan ukuran saluran yang ada harus dibuat sebanding dengan kapasitas maksimum limbah B3 yang tersimpan sehingga cairan yang masuk ke dalamnya dapat mengalir dengan lancar ke tempat penampungan. Sarana lain yang harus tersedia antara lain : peralatan dan sistem pemadam kebakaran, agar pengaman,Pembangkit listrik cadanga, Fasilitas pertiolongan pertama,Peralatan komunikasi,gudang tempat penyimpanan peralatan dan perlengkapan,Pintu darurat dan alarm

Hasil pengisian kuesioner mengenai bangunan penyimpanan limbah B3 menunjukkan rata-rata kondisi bangunan sudah sesuai walaupun beberapa memerlukan peningkatan kualitas. Sebanyak 55 bangunana penyimpanan sudah terlindung dari hujan, memiliki lantai bangunan kedap air,aman dari banjir dan berada ditempat yang teduh (54 hotel). Sebanyak 52 hotel dengan fasilitas penyimpanan LB3 sementara memiliki penerangan yang cukup baik. Sedangkan sebanyak 51 hotel telah memiliki ventilasi yang baik, memiliki APAR dan memiliki fasilitas P3K. 
Sedangkan item yang perlu diperhatikan adalah hanya sebanyak 25 hotel lokasi bangunananya berada dibawah 50 meter dari bangunan pertama dan hanya 19 hotel yang sudah dilengkapi dengan alarm pendeteksi api

Tabel 2 Kondisi Bangunan Penyimpanan LB3

\begin{tabular}{|l|c|c|}
\hline $\begin{array}{c}\text { Syarat Bangunan } \\
\text { LB3 }\end{array}$ & $\begin{array}{c}\text { Jumlah } \\
\text { akomodas } \\
\mathrm{i}\end{array}$ & $\begin{array}{c}\% \text { dari } \\
\text { total } \\
\text { sampe } \\
\text { I }\end{array}$ \\
\hline Terlindung dari hujan & 57 & $38 \%$ \\
\hline Ventilasi & 53 & $35 \%$ \\
\hline Lantai Bangunan & 56 & $37 \%$ \\
\hline APAR & 53 & $35 \%$ \\
\hline Blok Penyimpanan & 45 & $30 \%$ \\
\hline Pintu & 46 & $31 \%$ \\
\hline Alarm & 21 & $14 \%$ \\
\hline P3K & 52 & $35 \%$ \\
\hline Pintu Darurat & 25 & $17 \%$ \\
\hline Suhu terkendali & 56 & $37 \%$ \\
\hline Bebas Banjir & 56 & $37 \%$ \\
\hline Jarak dari gedung Utama & 26 & $17 \%$ \\
\hline Penerangan & 54 & $36 \%$ \\
\hline
\end{tabular}

\subsection{Pengelolaan Lanjutan}

Penyimpanan limbah B3 yang telah melampaui jangka waktu yakni 90 hari sejak limbah B3 dihasilkan, untuk limbah b3 yang dihasilkan sebesar $50 \mathrm{~kg}$ per hari atau lebih. Seratus delapan pulluh hari sejak limbah B3 dihasilkan untuk limbah B3 yng dihasilkan kurang dari $50 \mathrm{~kg}$ per hari untuk limbah B3 kategori I, yakni limbah B3 yang berdampak akut dan langsung terhadap manusia dan dapat dipastikan akan berdampak negatif terhadap lingkungan hidup. Tiga ratus enam puluh hari sejak limbah B3 dihasilkan untuk limbah yang dihasilkan untuk limbah kategori 2, yakni limbah B3 yang memiliki efek tunda dan berdampak tidak langsung terhadap manusia dan lingkungan hidup serta memiliki toksistias sub kronus atau kronis, baik dari sumber tidak spesifik atau sumber spesifik umum. Adapun pengelolaan lanjutan yang dapat dilakukan bagi hotel antara lain : membuat laporan dan melakukan pelaporan terhadap dinas terkait,Melakukan pemanfaatan, pengolahan atau penimbunan, yakni dengan. pengurangan limbah B3, substitusi bahan, modifikasi proses , penggunaan teknologi ramah lingkungan, melakukan kerjasama dengan pihak pengumpul limbah

Pengelolaan lanjutan yang dilakukan oleh hotel masih cukup rendah hal ini ditunjukkan hanya 32 hotel aktif membuat laporan atau log book LB3, kemudian 44 hotel melakukan pengurangan usaha LB3 dengan mensubstitusi bahan yang lebih ramah lingkungan dan menggunakan teknologi ramah lingkungan. Kemudian tidak ada yang melakukan pengolahannya sendiri, hal ini wajar mengingat pengolahan LB3 memerlukan penanganan yang serius. Sebanyak 26 hotel telah memiliki kontrak dengan pihak ketiga pengumpul LB3. Berikut ini adalah hasil pengisian kuesioner untuk kemasan penyimpanan limbah B3

Tabel 3 Tingkat Pengelolaan Lanjutan LB3 pada akomodasi wisata

\begin{tabular}{|l|c|c|}
\hline \multicolumn{1}{|c|}{$\begin{array}{c}\text { Bentuk Pengelolaan } \\
\text { Lanjutan }\end{array}$} & Jumlah & \\
\hline $\begin{array}{l}\text { Membuat Laporan dan } \\
\text { melakukan pelaporan }\end{array}$ & 34 & $23 \%$ \\
\hline $\begin{array}{l}\text { Melakukan usaha } \\
\text { pengurangan LB3 }\end{array}$ & 49 & $33 \%$ \\
\hline $\begin{array}{l}\text { Melakukan kerjasama } \\
\text { dengan pihak ketiga }\end{array}$ & 38 & $25 \%$ \\
\hline $\begin{array}{l}\text { melakukan pengelolaan } \\
\text { LB3 sendiri }\end{array}$ & 0 & $0 \%$ \\
\hline $\begin{array}{l}\text { Memilik kontrak dengan } \\
\text { penyedia jasa pengumpul } \\
\text { LB3 }\end{array}$ & 26 & $17 \%$ \\
\hline
\end{tabular}

\section{KESIMPULAN DAN SARAN}

\section{Kesimpulan}

1. Total kegiatan yang memiliki ijin tempat penyimpanan sementara limbah B3 adalah sebanyak 24 kegiatan, akomodasi wisata yang telah memiliki fasilitas penyimpanan 
sementara limbah B3 namun belum berijin sebanyak 25 hotel. Kegiatan yang masih dalam proses pengurusan ijin sebanyak 3 hotel sementara sisanya belum memiliki ijin maupun fasilitas.

2. Hotel dengan jumlah kamar diatas 400 unit semuanya telah memilki ijin tempat penyimpanan sementara limbah B3. Sementara hotel dengan kapasitas kamar 300-400 unit sebanyak $70 \%$ telah memiliki ijin penyimpanan sementara limbah B3. Hotel dengan kapasitas kamar 100-300 unit sebanyak $50 \%$ telah memiliki ijin tempat penyimpana sementara limbah B3. Sedangkan hotel atau villa dengan unit kamar dibawah 100 hanya $4 \%$ yang sudah memiliki ijin tempat penyimpanan sementara limbah B3.

3. Sebanyak $70 \%$ kegiatan yang belum memilik ijin tempat penyimpanan berupa villa dan kurang mendapat informasi mengenai ijin tempat penyimpanan limbah B3 serta hanya menghasilkan

4. limbah B3 dalam jumlah sangat sedikit sementara untuk pengelolaan dengan bekerjasama dengan pengumpul harganya cukup mahal.

\section{Saran}

1. Memberikan sosialisasi kepada pelaku pariwisata, industri maupun fasilitas umum yang telah memiliki fasilitas penyimpanan sementara namun tidak memiliki ijin agar segera melakukan pengurusan ijin penyimpanan sementara.

2. Memanfaatkan produk-produk ramah lingkungan dan mereduksi jumlah limbah dan sampah.

\section{DAFTAR PUSTAKA}

Badan Pusat Statistik. 2019. Kuta Selatan dalam Angka 2019. Badung

Badan Pengendalian Dampak Lingkungan.1995. Keputusan Bapedal Nomor 1 Tahuan 1995 tentang Tata Cara dan Persyaratan Teknis Penyimpanan dan Pengumpulan Limbah B3

Kementrian Lingkungan Hidup dan Kehutanan.2009. Peraturan Menteri Lingkungan Hidup Nomor 30 Tahun 2009 tentang tata laksana perizinan dan pengawanan pengelolaan limbah B3 serta Pengawasan Pengelolaan Limbah B3 serta Pengawasan Pemulihan Akibat Pencemaran Limbah B3.

La Grega, M.D., P.L Buckingham, dan J.C. Evans.1994. Hazardous Waste Management. New York: McGraw-Hill 1146pp

Pemerintah republik Indonesia.2009. Undangundang Nomor 32 Tahun 2009 Tentang Perlindungan dan Pengelolaan Lingkungan Hidup

Pemerintah Republik Indonesia. 2014. Peraturan Pemerintah Republik Indonesia Nomor 101 Tahun 2014 Tentang Pengelolaan Limbah B3

Palar, H. 1994. Pencemaran dan Toksikologi Logam Berat. Rineka Cipta. Bandung

Pemerintah Kabupaten Badung. 2010. Peraturan Bupati Badung Nomor 55 Tahun 2010 Tentang Tata Laksana Perizinan dan Pengawasan Limbah B3 serta pengawasan pemulihan akibat pencemaran Limbah B3 